\title{
METHODS FOR STUDYING AND ASSESSING CYTOGENETIC CHANGES IN BONE MARROW CELLS OF LABORATORY ANIMALS RECEIVING GENE-MODIFIED
}

\author{
N.A.Nuraliyev ${ }^{1}$, A.Kh.Allanazarov ${ }^{2}$, M.S.Gildiyeva ${ }^{3}$, D.R.Sobirova ${ }^{4}$ \\ ${ }^{1}$ Bukhara State Medical Institute, \\ ${ }^{2}$ Termez branch of the Tashkent State Medical Academy, \\ ${ }^{3}$ Republican Specialized Scientific and Practical Medical Center of Oncology and Radiology of the Ministry of Health of the \\ Republic of Uzbekistan, \\ ${ }^{4}$ Tashkent Medical Academy
}

\begin{abstract}
The aim was to study cytogenetic changes in bone marrow cells of laboratory animals that received and did not receive a genetically modified (GM) product (GM-soy) in a comparative aspect. It was found that in the group of white outbred rats that received GM-soy, cytogenetic changes were found in the cells of the red bone marrow, expressed in partial inhibition of cell proliferation due to the cytotoxic effect. They also had polyploidy (5.35\%) and aneuploidy (5.35\%) in 10.7\% of cases. In addition, this group contained cells with mitotic pathology - chromosome scattering, chromosome pulverization, impaired spiralization and despiralization of chromosomes, premature spiralization of chromosomes, delayed mitosis at the prophase stage. In the group of animals that did not receive soy with and without GM in the cells, there were metaphase plates with a normal karyotype. The mitotic activity of bone marrow cells in the control group was higher (MI - 9\%) than in the first (MI - 3\%) and the second group (MI - 5\%).
\end{abstract}

Keywords:

experimental animals, bone marrow cells, cytogenetic changes, genetically modified product.

Article Received: 18 October 2020, Revised: 3 November 2020, Accepted: 24 December 2020

Genetically modified (GM) organisms are plant or animal organisms, the genotype of which has been changed in a way that is not natural for nature, using methods of genetic engineering to give the body new properties: resistance to herbicides, pests, diseases and salinity, to the action of high and low temperatures, increasing productivity, calorie content; to solve the problems of cleaning the environment from organic pollution and heavy metals; to ensure the synthesis of certain compounds in the plant organism and the use of plants for the production of these compounds $[3,9,10]$.

Genetic changes are made for scientific and / or economic purposes, differ in the change in the genotype of the organism, in contrast to the random, characteristic of a natural mutational process. The main trait inherent in most GM plants is herbicide and pest resistance. [1, 5, 7, 12]. It has been proven that the cultivation of GM soybeans does not have a single positive moment for the organism.

The most serious risks associated with the products of genetic engineering are combined into 2 main groups: food and environmental [2,8]:

Nutritional - weakening of the immune system; the occurrence of allergic reactions; development of pathologies associated with the accumulation of pesticides in the human body, introduced by the used GM products, including GM soy.

Ecological - loss of the diversity of the gene pool of wild relatives of cultivated plants due to their cross-pollination with related GM plants; pollution of water resources by the use of pesticides; depletion and disruption of natural soil fertility associated with the suppression of GM plant toxins of the vital activity of soil invertebrates and normal microflora; accelerated plant growth to a much greater extent than that of traditional crops. 
In general, the above studies point to insufficient substantiation of the safety of GM products of plant origin for humans and the environment.

Many authors believe that at present it is important to solve an urgent problem, to correlate the rate of environmental change with the adaptive capabilities of human populations; in addition, it is necessary to assess the extent to which changes occurring in the biosphere affect the rate of the mutational process $[6,7,11] \ldots$

The results of biological monitoring of human populations have shown that at present there is not only an increase in hereditary pathology, but also an increase in the frequency of diseases with a genetic component. The danger of induced mutagenesis is that newly emerging mutations have a negative impact on the fitness of the population and on the health of the population.

In this regard, new research in this direction is relevant and in demand at the present time.

The purpose of this study was to study and evaluate cytogenetic changes in bone marrow cells of laboratory animals that received and did not receive a GM product (GM soy) in a comparative aspect.

\section{Materials and methods}

To perform the planned studies, 30 white outbred rats weighing 150-180 grams of both sexes were used, kept in standard vivarium conditions - at a relative humidity of $50-60 \%$, a temperature of $220 \mathrm{C}$, a light regime (12 hours of darkness and light). Keeping laboratory animals, feeding and caring for them, selection of animals, cleaning and disinfection of the vivarium premises were carried out in accordance with the approved recommendations [4].

When working with experimental animals, all ethical principles of working with laboratory animals and the rules of biological safety were strictly observed [4].

When carrying out cytogenetic studies, all operations when working with growth media and preparations were carried out under sterile conditions using a laminar box. The buffers were prepared in bidistilled water, filtered through membrane filters (0.22 $\mu \mathrm{m}$ "Millipor", Germany) and autoclaved at $1.2 \mathrm{~atm} .30$ minutes. Before use, glassware is pre-sterilized at $1600 \mathrm{C}$ for 120 minutes. Equipment, fixtures, utensils made of polymeric materials were exposed to ultraviolet light for 30 minutes. For experimental studies, bone marrow was selected from the femur of laboratory animals during dissection of the animal.

All laboratory animals were divided into the following groups:

The first group - white outbred rats $(\mathrm{n}=$ 12), who received GM-soy with cooked food for 30 days at 0.02-0.03 grams per one laboratory animal;

The second group - white outbred rats $(\mathrm{n}=$ 12), who received non-GM-modified regular soybeans together with cooked food for 30 days at 0.02-0.03 grams per one laboratory animal;

The third group consisted of white outbred rats $(n=6)$, who received a standard diet without GM soybeans and regular soybeans for 30 days.

Soybeans grown abroad and imported to our country only for scientific research work were used as a GM product in the experiments.

Using the method of polymerase chain reaction (PCR), the presence of the $35 \mathrm{~S}+\mathrm{FMV}$ promoter in the GM soy under study was revealed, which proves that the studied soy is a GM product.

Cytogenetic changes in rat bone marrow cells were studied using a direct method. The execution of the method included the following stages:

- red bone marrow was washed from the femur of outbred rats involved in the experiment of all three study groups with the RPMI 1640 nutrient medium with $0.04 \%$ colchicine (which destroys the division spindle and chromosomes do not diverge to the poles during mitosis, forming a polyploid organism) into a centrifuge test tube and incubated for 2-2.5 hours in a thermostat at 370C.

- then incubated with a hypotonic $\mathrm{KCl}$ solution for 40 minutes in a thermostat at $370 \mathrm{C}$. 
- after hypotension, they were treated three times with a fixative in the proportion of one part of glacial acetic acid and three parts of 960-1000 ethyl alcohol.

- the resulting precipitate was applied to a previously cleaned defatted glass slide and stained with Giemsa dye.

- the search for metaphases was carried out under a Leica microscope (Germany) at a magnification of 200 times, the analysis of metaphase plates at a magnification of 1000 times, in each sample, from 15 to 25 cells with metaphase plates were analyzed.

In the preparations, the number of cells in division was counted under a microscope, the mitotic (MI) index was calculated using the formula:

$$
\text { MI }=\frac{\text { Number of cellsin division }}{1000} \times 100
$$

Statistical processing was carried out by the generally accepted methods of variation statistics. To compile an idea of the sample as a whole, the principles of descriptive statistics and the indicators mean (M) and discrete data presented as a percentage (\%) were used.

Table 1 The number of experimental animals and metaphase plates found during research

\begin{tabular}{|l|c|c|}
\hline Group & \multicolumn{2}{|c|}{ amount } \\
\cline { 2 - 3 } & animal & metaphases \\
\hline Group 1 (GM-product - GM-soy) & 12 & 75 \\
\hline Group 2 (soy without GM) & 12 & 75 \\
\hline Group 3 (standard diet - control) & 6 & 75 \\
\hline
\end{tabular}

At the end of the prometaphase, the chromosomes are located in the equatorial plane of the spindle at approximately the same distance from both poles of division, forming a metaphase plate. Metaphase plates are an accumulation of chromosomes in the plane perpendicular to the division axis (equatorial plane), in which the chromosomes are located equatorially in the metaphase of mitosis (the second phase of somatic cell division). The number of chromosomes in rats is normally 42 (diploid set).

The analysis showed that due to the low mitotic activity of bone marrow cells in the first group (treated with GM-soy), only in 4/12 (30.0\%) laboratory animals, metaphase plates were found in bone marrow samples (Table 2). Of all the metaphases to be analyzed (75 in total) in
Research results. For the analysis, cells of the red bone marrow were used, in which elements of the mitotic apparatus were detected (Table 1).

Table 2 Indices of cytogenetic changes in bone marrow cells of laboratory animals treated with GM and without GM soy

\begin{tabular}{|l|l|l|l|}
\hline \multirow{2}{*}{ Group } & \multicolumn{3}{|c|}{ Types of aberrations } \\
\cline { 2 - 4 } & Polyploidy & Aneuploidy & Pathology of mitosis \\
\hline
\end{tabular}




\begin{tabular}{|l|l|l|c|}
\hline First group & $5,35 \pm 2,6 \% *$ & $5,35 \pm 2,6 \% *$ & $\begin{array}{c}\text { Chromosome scattering, } \\
\text { Chromosome pulverization, } \\
\text { Delayed mitosis in prophase }\end{array}$ \\
\hline Second group & "Absence" & "Absence" & $\begin{array}{c}\text { Pulverization of chromosomes, } \\
\text { K-mitosis }\end{array}$ \\
\hline Third group & "Absence" & "Absence" & "Absence" \\
\hline
\end{tabular}

Note $*$ - reliability indicator $(\mathrm{p}<\mathbf{0 . 0 5})$.

In the remaining $(70 \%)$ bone marrow samples of white outbred rats of this experimental group, metaphase plates were absent, but there were blast cells (cells at the stage preceding mitosis) and cells with mitotic pathology chromosome pulverization (Fig. 1 and Fig. 2).

In addition, in the course of our research, we found cells with other

pathologies of mitosis - impaired spiralization and despiralization of chromosomes (Fig. 3), as well as premature spiralization of chromosomes, delayed mitosis at the prophase stage.

Figure: 1. Bone marrow cells of laboratory animals treated with GM soy (first group). Pulverization of chromosomes (approx. X10, vol. X100)

Figure: 2. Bone marrow cells of laboratory animals treated with GM soybeans (first group). Pulverization of chromosomes (approx. $X$ 10, vol. $X$ 100)

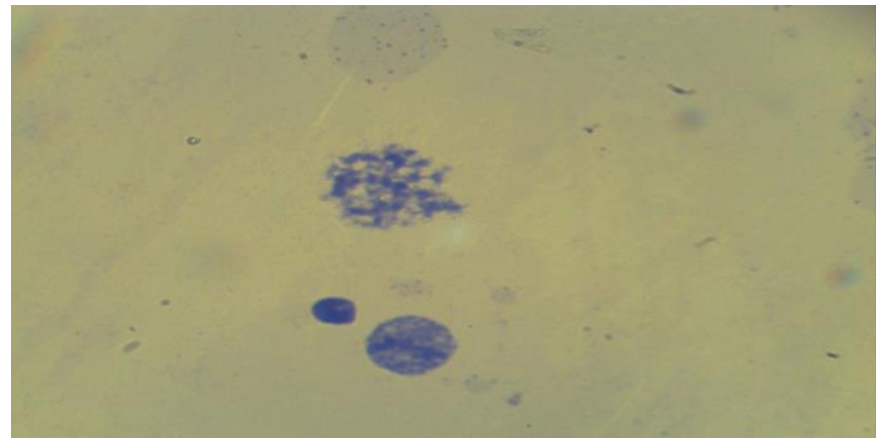

Figure: 3. Bone marrow cells of laboratory animals treated with GM soybeans (first group). Violation of spiralization and despiralization of chromosomes (approx. X10, Ob.x100) 
Below we present the result of microscopic examination of the red bone marrow for the purpose of studying cytogenetic changes in laboratory animals of the first group (taking GM soy). In fig. 4 shows the detected chromosome aneuploidy.

Figure: 4. Cells of the bone marrow of laboratory animals, poluchavshix GM-soy (primary group). Aneuploidy chromosome. (Ok. X10, Ob. X100)

Experimental studies on laboratory animals proved that the used GM product (GM soy) led to cytogenetic changes in the cells of highly proliferating tissues, such as the red bone marrow of white outbred rats.

There is a partial inhibition of the proliferation of bone marrow cells due to the cytotoxic effect, which can lead to cytopenia.

In the second group, polyploid (polyploidy) and aneuploid (aneuploidy) karyotypes were not found in laboratory animals in the metaphase plates of the red bone marrow.

In all (75 in total) analyzed metaphases, the karyotype was not changed, no deviations were observed. The cells did not contain genomic abnormalities; all metaphases had a normal karyotype (42 chromosomes).

However, in $8.3 \%$ (1 case) bone marrow samples of rats of the second group, where all white outbred rats received soy without GM, cells with mitosis pathology were found - chromosome pulverization, K-mitosis, as well as in red bone marrow cells of white outbred rats the first group. This fact indicates that in laboratory animals that ate an unusual food for them (soybeans), some cytogenetic changes in the red bone marrow were noted.

But basically, no cytogenetic changes were observed and a normal karyotype was found (Fig. $5)$.

Figure: 5. Cells of bone marrow laboratory animals, poluchavshix soybean without GM (second group). Normal karyotype (Ok. X10, Ob. X100)

In the third group (control group), whose representatives were kept on a standard vivarium ration and did not receive GM soy and without $\mathrm{GM}$, in all samples of red bone marrow the cells had only metaphase plates with a normal karyotype (Fig. 6 - early metaphase; Fig. 7 - late metaphase).

Thus, cytogenetic studies of the red bone marrow of laboratory animals showed that white outbred rats receiving GM soy exhibited various pathologies of mitosis - chromosome scattering, 
chromosome pulverization, and delayed mitosis in prophase. In animals that did not receive GM soy such cytogenetic changes were not observed, a normal karyotype was found.

Figure: 6. Bone marrow cells of laboratory animals that received a standard diet (third group control). Normal karyotype, early metaphase. (Approx.x10, Ob.x100)

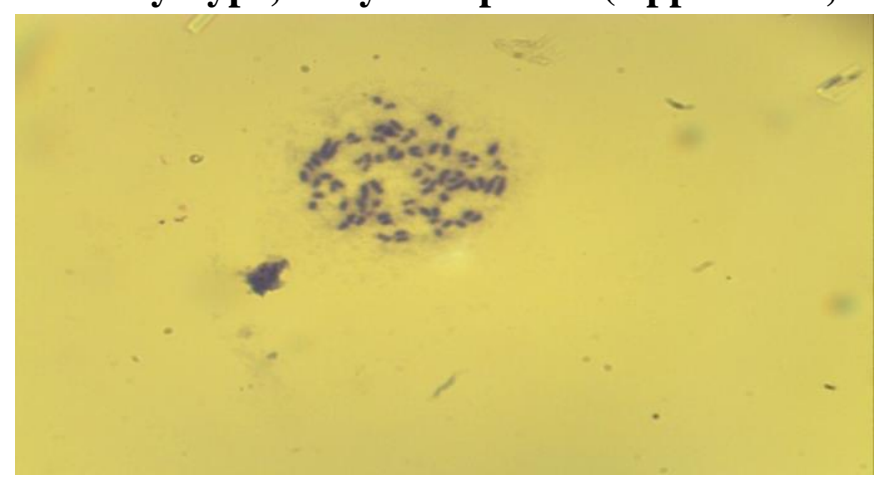

Figure: 7. Bone marrow cells of laboratory animals that received a standard diet (third group control). Normal karyotype, late metaphase (approx. X10, Ob.x100)

The results obtained show that the mitotic activity (Table 3 ) of bone marrow cells in the control group (third group) of white outbred rats was higher (MI - 9\%) than in the experimental groups - in the first group MI - 3\% and in the second group MI - 5\%.
Thus, it was found that in white outbred rats that received GM soybeans, mitotic activity decreases, which is expressed in a decrease in the mitotic index.

Table 3 Mitotic activity of rat bone marrow cells

\begin{tabular}{|c|c|c|}
\hline \multirow{2}{*}{ Group } & \multicolumn{2}{|c|}{ amount } \\
\cline { 2 - 3 } & Dividing / cells & MI, \% \\
\hline First group & $30 / 1000$ & 3 \\
\hline Second group & $50 / 1000$ & 5 \\
\hline Third group (control) & $90 / 1000$ & 9 \\
\hline
\end{tabular}

The method of studying and evaluating cytogenetic changes in the cells of the red bone marrow of laboratory animals receiving a GM product in a comparative aspect leads to an improvement in the performance of cytogenetic studies, thereby improving the assessment of the effect of GM products on cells of the red bone marrow of laboratory animals (white outbred rats) in experimental research. In addition, this technique makes it possible to increase the efficiency of cytogenetic studies when studying the effect of a GM product on an organism in an experiment.

Based on the studies carried out, cytogenetic changes in the bone marrow cells of laboratory animals that received the GM product were studied and evaluated. The data obtained make it possible to use the proposed recommendations to improve the efficiency of the method for studying and assessing cytogenetic 
changes in the cells of the red bone marrow of laboratory animals in experimental studies.

\section{Conclusion}

1. It was found that in the group of white outbred rats receiving GM-soy, cytogenetic changes were found in the cells of the red bone marrow, expressed in partial inhibition of cell proliferation due to cytotoxic action, which can lead to cytopenia.

2. Of all the metaphases to be analyzed in the bone marrow cells of laboratory animals of the first group, $10.7 \%$ were found to have altered karyotypes - polyploidy (5.35\%) and aneuploidy $(5.35 \%)$. In animals of other groups (the second and third groups), such changes were not observed.

3. In the bone marrow samples of white outbred rats of the first group involved in the experiment, there were blast cells and cells with mitotic pathology - chromosome scattering, chromosome pulverization, chromosome spiralization and despiralization, premature chromosome spiralization, mitosis delay at the prophase stage.

4. In some laboratory animals, which were fed soy without GM (second group), a decrease in the proliferation of bone marrow cells was found; in all analyzed metaphases, the karyotype was not changed. The cells did not contain genomic abnormalities; all metaphases had a normal karyotype (42 chromosomes).

5. The mitotic activity of bone marrow cells in the control group (third group) of white outbred rats was higher (MI - 9\%) than in the experimental groups - in the first (MI - 3\%) and the second group (MI - 5\%). In white outbred rats receiving GM soybeans, mitotic activity decreases, which is expressed in a decrease in the mitotic index.

6. In the group of animals that did not receive soy with and without GM (third group control), all bone marrow samples in cells had metaphase plates with normal karyotype.

\section{References}

[1] Derevenschikova M.I., Syromyatnikov M.Yu. The use of molecular genetic methods for microbiological control of food products // Technics and technology of food production. - 2018. - No. 4. - P.87-113.

[2] Dronik G.V., Black I.V. The content of medium molecules in the blood serum of rats using traditional and transgenic soy // Bulletin of modern research. - 2017. - No. 61. - P.7-8.

[3] Zakirova G.Sh., Papunidi K.Kh., Kadikov I.R. Influence of diets containing genetically modified soybeans on the animal organism // Veterinary doctor. - 2019. - No. 4. - P.37-43.

[4] Nuraliyev N.A., Bektimirov A.M.-T., Alimova M.T., Suvonov K.Zh. Rules and methods of working with laboratory animals in experimental microbiological and immunological research // Methodical manual. - Tashkent, 2016 .-- 33 p.

[5] Pavlovskaya N.E., Lushnikov A.V., Polekhina N.N., Solokhina I.Yu., Gneusheva I.A. Influence of genetically modified soybeans on body weight and reproductive activity of white laboratory mice // Bulletin of Science and Education. - 2018. - No. 2. P.1-12.

[6] Sobirova D.R., Nuraliyev N.A., Ginatullina E.N. Results of experimental studies on the study and assessment of the mutagenic activity of a genetically modified product // Problems of Biology and Medicine. Samarkand, 2017. - No. 1. - S. 180-184.

[7] Sobirova D.R., Nuraliyev N.A., Nosirova A.R., Ginatullina E.N. Study of the effect of a genetically modified product on mammalian reproduction in experiments on laboratory animals // Infection, immunity and pharmacology. - Tashkent, 2017. - No. 2. - S. 195-200.

[8] Tutelyan V.A. Ensuring the safety of genetically modified organisms for food production // Bulletin of the Russian Academy of Sciences. - 2017. - Volume 87. - №4. - S.342-347. 
[9] Tyshko N.V. Control over genetically modified organisms of plant origin in food products: scientific substantiation and methodological support // Nutrition issues. 2017. - Volume 86. - No. 5. - pp. 29-33.

[10] Global Status of Commercialized Biotech / GM Crops in 2014, Pocket K No.16, ISAAA, p. five.

[11] Nuraliyev N.A., Sobirova D.R., Baltaeva K.A., Ginnatullina E.N. Effect of genetically modified product on reproduction function, biochemical and hematology indexes in experimental study // European Science Review. - Austria, Vienna, 2017 .-- N1. P.94-95.

[12] Willems S. Fraiture MA, Deforce D., De Keersmaecker SC, De Loose M., Ruttink T., Herman P., Van Nieuwerburgh F., Roosens N. Statistical framework for detection of genetically modified organisms based on Next Generation Sequencing // Food Chemistry. - 2016. - Vol. 192. - P.788-798. 